\title{
Using rat operant delayed match-to-sample task to identify neural substrates recruited with increased working memory load
}

\author{
Christina Gobin, ${ }^{1,2,3}$ Lizhen $\mathrm{Wu},{ }^{1}$ and Marek Schwendt ${ }^{1,2}$ \\ ${ }^{1}$ Department of Psychology, University of Florida, Gainesville, Florida 32611, USA; ${ }^{2}$ Center for Addiction Research and Education, \\ University of Florida, Gainesville, Florida 32610, USA; ${ }^{3}$ Department of Pharmacodynamics, University of Florida, Gainesville, \\ Florida 32610, USA
}

\begin{abstract}
The delayed match-to-sample task (DMS) is used to probe working memory (WM) across species. While the involvement of the PFC in this task has been established, limited information exists regarding the recruitment of broader circuitry, especially under the low- versus high-WM load. We sought to address this question by using a variable-delay operant DMS task. Male Sprague-Dawley rats were trained and tested to determine their baseline WM performance across all (0- to 24-sec) delays. Next, rats were tested in a single DMS test with either 0- or 24-sec fixed delay, to assess low-/high-load WM performance. c-Fos mRNA expression was quantified within cortical and subcortical regions and correlated with WM performance. High WM load up-regulated overall c-Fos mRNA expression within the PrL, as well as within a subset of mGlu5+ cells, with load-dependent, local activation of protein kinase $\mathrm{C}(\mathrm{PKC})$ as the proposed underlying molecular mechanism. The PrL activity negatively correlated with choice accuracy during high load WM performance. A broader circuitry, including several subcortical regions, was found to be activated under low and/or high load conditions. These findings highlight the role of mGlu5- and/or PKC-dependent signaling within the PrL, and corresponding recruitment of subcortical regions during high-load WM performance.
\end{abstract}

Working memory (WM) confers the ability to temporally maintain and manipulate information in the absence of relevant sensory input to guide goal-directed behavior (Baddeley 1992; Dosher 2006). In addition, WM contributes to and overlaps with other domains of executive functioning such as attention, cognitive flexibility, and inhibitory control. While WM function changes throughout the life span, pronounced WM impairment has been characterized in a number of neuropsychiatric disorders including schizophrenia, substance use disorders, and ADHD (Chai et al. 2018). The susceptibility of WM to disruptions stems from the fact that it is a memory system with limited capacity, in which stored information undergoes rapid decay. Even if the amount of information in WM does not exceed its capacity, it can impose varied demand on WM processing. This is commonly referred to as "WM load" and can also be described as the amount of information, or the duration for which that information must be held "online" to solve a particular problem (Dosher 2006). Imaging studies in humans and nonhuman primates reproducibly showed that the dorsolateral prefrontal cortex (dIPFC) is a key brain structure activated during WM performance, and further that neural activity within this brain region correlates with the WM load (Braver et al. 1997; Manoach et al. 1997; Toepper et al. 2014; Brzezicka et al. 2018). The medial prefrontal cortex (mPFC) in rats is a cortical region thought to be analogous to the human and primate dlPFC, in terms of anatomical connections and function (Brown and Bowman 2002; Seamans et al. 2008). Accordingly, a number of studies using diverse tasks showed that activity within the rat mPFC is required for "normal" WM performance (e.g., see Jung et al. 1998; Horst and Laubach 2009; Yang et al. 2014). One of the most commonly used behavioral tasks to assess WM in both humans and animals is the (variation of) delayed match-to-sample task (DMS) (Lind et al.

\section{Corresponding author: schwendt@ufl.edu}

Article is online at http://www.learnmem.org/cgi/doi/10.1101//m.052134.120.
2015; Daniel et al. 2016). While in some WM tasks (such as water radial arm maze) increased memory load is related to higher number of items to be retained (e.g., see Bimonte et al. 2003; Bratch et al. 2016), in DMS task (and delayed alternation task) the same goal is achieved by increasing the duration (delay) required to hold information online (e.g., see Sloan et al. 2006; George et al. 2008; Bizon et al. 2012; Radley et al. 2015; Gobin et al. 2019). Operant DMS tasks involve presentation of a stimulus, followed by a delay period and a subsequent choice phase, wherein the selection of a matching stimulus is required to obtain a reward. The advantage of this task is that the delay period can be easily adjusted to control the difficulty of the task such that increasing the delay imposes greater WM load. The current study adopted a version of the rat operant DMS task that has been previously shown to require activation of the mPFC (Sloan et al. 2006). A more recent study by (Hernandez et al. 2018) using the same DMS task has identified that the activity of subtype 5 metabotropic glutamate receptor (mGlu5) within this brain region is necessary to maintain high choice accuracy. To further highlight the key role of the mPFC, large hippocampal lesions do not have an impact on the DMS task performance (Sloan et al. 2006). And while, in WM tasks that rely more heavily on spatial navigation (such as Y-maze task, or delayed alternation task in a T-maze) where recruitment of the hippocampus has been documented (Vorhees and Williams 2014), detailed investigation of hippocampal activity (or a broader circuitry) involved in the operant DMS task has not been conducted. A recent meta-analysis of human functional neuroimaging studies using the DMS task to investigate WM, confirmed the

(C) 2020 Gobin et al. This article is distributed exclusively by Cold Spring Harbor Laboratory Press for the first 12 months after the full-issue publication date (see http://learnmem.cshlp.org/site/misc/terms.xhtml). After 12 months, it is available under a Creative Commons License (Attribution-NonCommercial 4.0 International), as described at http://creativecommons.org/licenses/by-nc/4.0/. 
role of the dIPFC, but also implicated a broader circuitry composed of other cortical areas (e.g., premotor and orbitofrontal cortex), as well as subcortical structures (e.g., thalamus, amygdala) (Daniel et al. 2016). It also revealed that variations in the DMS task parameters, such as the use of verbal versus nonverbal stimuli, results in distinct recruitment of WM networks. And finally, this metaanalysis (and other published evidence; e.g., see Chen and Desmond 2005) suggests that activity within some, but not all, human WM-related circuits track variations in WM load.

The current study was motivated by the fact that (besides the $\mathrm{mPFC}$ ), it is currently unknown which neural circuits are recruited during the operant WM task in rats, and how the activity (or the recruitment) of these circuits varies with increasing WM load (delay). To address this knowledge gap, we conducted an analysis of $c$-Fos expression (a well-established marker of recent neuronal activity; Morgan and Curran 1991; Gallo et al. 2018) throughout several brain regions in rats trained in the operant DMS task and tested under fixed low- and high-load WM conditions. Further, this study also explored the relationship between WM performance and neural activity (c-Fos mRNA levels) in the selected brain regions. Lastly, in order to characterize candidate neural and molecular substrates of WM, this study analyzed two variables related to mGlu5 receptor activity in the prelimbic cortex (PrL) immediately following the final WM test: $c$-Fos expression in a subset of mGlu5+ neurons, and the activity of mGlu5 partner protein kinase, protein kinase $\mathrm{C}$ (PKC).

\section{Results}

\section{Delayed match-to-sample task performance under variable and fixed delay conditions}

All rats were successfully trained in the DMS task reaching the predetermined testing criterion in $46.65 \pm 3.34 \mathrm{~d}$. The DMS task performance (percent correct responses across the variable 0 - to 24 -sec delay set) was evaluated over two consecutive 5-d testing blocks. Repeated measures two-way ANOVA was conducted with Block and Delay as the within-subject factors. We found a main effect of Delay $\left(F_{(6,108)}=176.6, P<0.0001\right)$ (Fig. 1B), but not Block $\left(F_{(1,18)}=0.37\right.$, n.s.). The number of trials completed did not differ between Block 1 and Block 2 (data not shown). This suggests a relatively stable overall DMS performance that was sensitive to demand (delay). Prior to the final DMS test, rats were subdivided into three groups: home cage control, fixed 0 -sec, and fixed 24-sec delay groups. Two-way ANOVAs were conducted with Delay as the within-subject factor and Group as the betweensubjects factor for each Block that revealed no pre-existing between-group differences in baseline DMS responding. There was no effect of Group $\left(F_{(2,16)}=0.58\right.$, n.s. $)$ and no Group $\times$ Delay interaction for Block $1\left(F_{(12,96)}=1.06\right.$, n.s. $)$. Also, there was no effect of Group $\left(F_{(2,16)}=0.63\right.$, n.s. $)$ and no Group $\times$ Delay interaction for Block $2\left(F_{(12,96)}=0.45\right.$, n.s. $)$. The DMS task performance during the final test was analyzed using unpaired $t$-tests to compare percent correct responses (Fig. 1C) and the number of trials completed (Fig. 1D) under the conditions of a fixed (0- or 24-sec) delay. Rats performed significantly worse under the high-load working memory conditions (24-sec delay), when compared with the low-load group $\left(0\right.$-sec delay; $\left.t_{(13)}=13.6, P<0.0001\right)$ (Fig. $\left.1 \mathrm{C}\right)$. Rats in the 0 -sec delay group completed more trials than rats in the $24 \mathrm{sec}$ delay group $\left(t_{(13)}\right.$ $=10.42, P<0.0001)$ (Fig. 1D). The omission rate in both groups was very low (zero to four omissions per test; data not shown).

\section{c-Fos mRNA expression after a fixed delay DMS test}

$c$-Fos mRNA levels, used here as a marker of recent neuronal activity, were quantified across several rat brain regions immediately following the final (fixed delay) DMS test, or in age-matched control rats that remained undisturbed in their home cage. c-Fos mRNA was quantified as the total mRNA puncta per target region of interest (ROI) averaged from two sections per brain regions for each rat. The ROIs analyzed in the current study have been previously implicated in the regulation of (1) WM performance-prelimbic cortex (PrL), dorsomedial striatum (DmS), nucleus accumbens (NAc), subregions of the hippocampus (CA1 and CA3), perirhinal cortex $(\mathrm{PrH})$, nucleus reuniens (NRe), and more broadly in (2) behavioral flexibility (orbitofrontal cortex [OFC]), (3) reward-based decisionmaking (dorsolateral striatum [DIS]), (4) served as a positive control for the motor function-related neural activity (primary motor cortex [M1]), or is known to be involved in non-WM type of memory (central amygdala $[\mathrm{CeA}]$ ). See the Discussion section for the

A
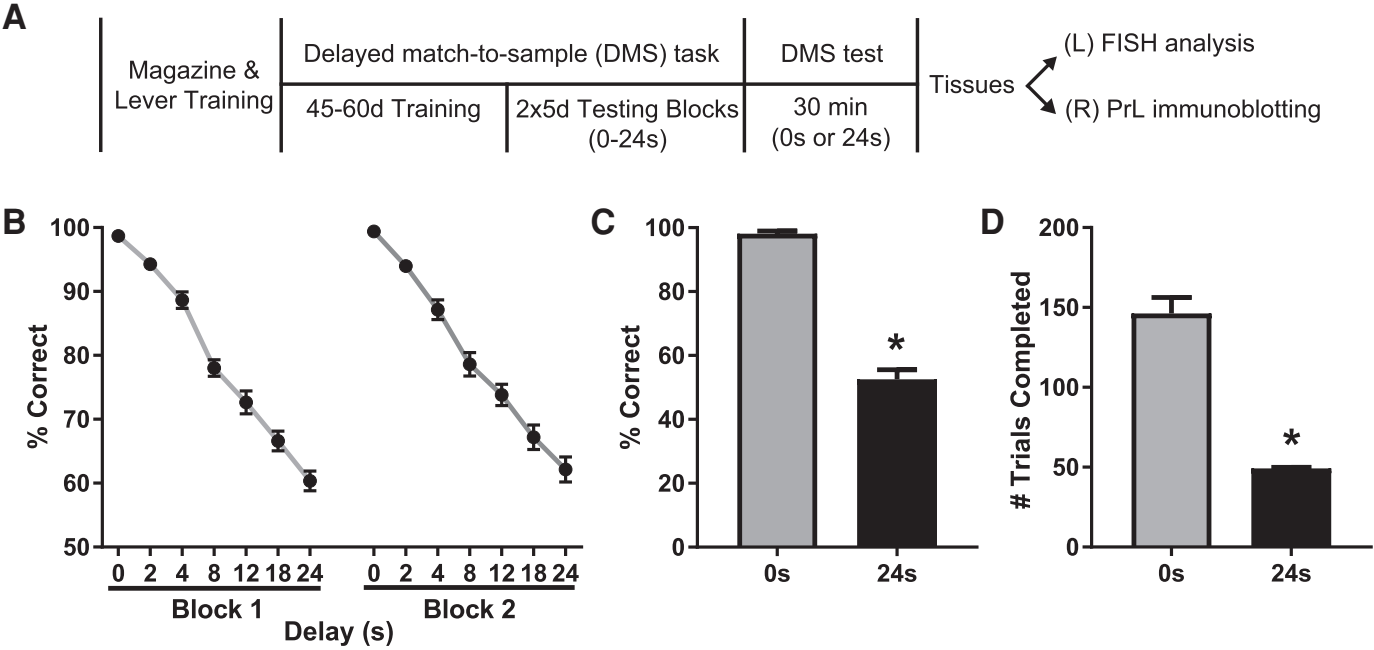

Figure 1. Delayed match-to-sample task performance under variable, or fixed delay conditions. $(A)$ Experimental timeline. The left hemisphere $(\mathrm{L})$ was processed for the FISH analysis, while the PrL tissue from the right hemisphere (R) was processed for immunoblotting. (B) Baseline working memory (WM) testing. Delay-dependent DMS task performance (\% correct) under variable 0 - to 24 -sec delay conditions for the period of two consecutive testing blocks. (C, $D$ ) Single DMS test. Rats' DMS task performance, percent correct responses $(C)$, and the number of trials completed $(D)$ during the single 30-min test with either 0 - or 24 -sec fix delay. Mean \pm SEM, $\left(^{*}\right) P<0.05$ versus 0 -sec group, $n=7-8 /$ group. 
A

3.72

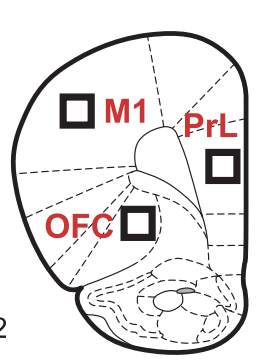

B

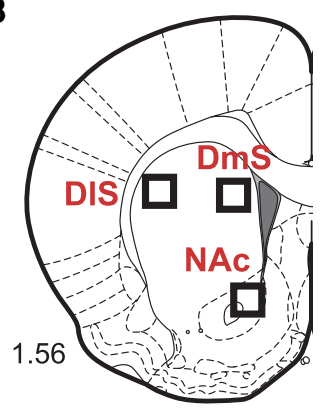

C

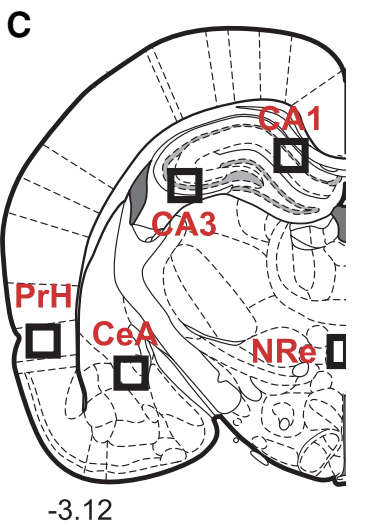

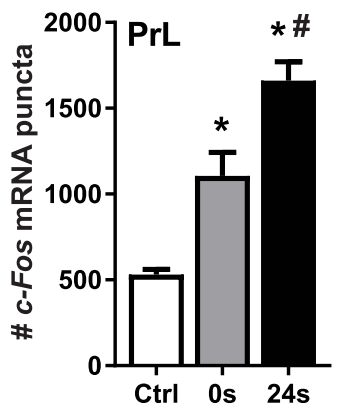
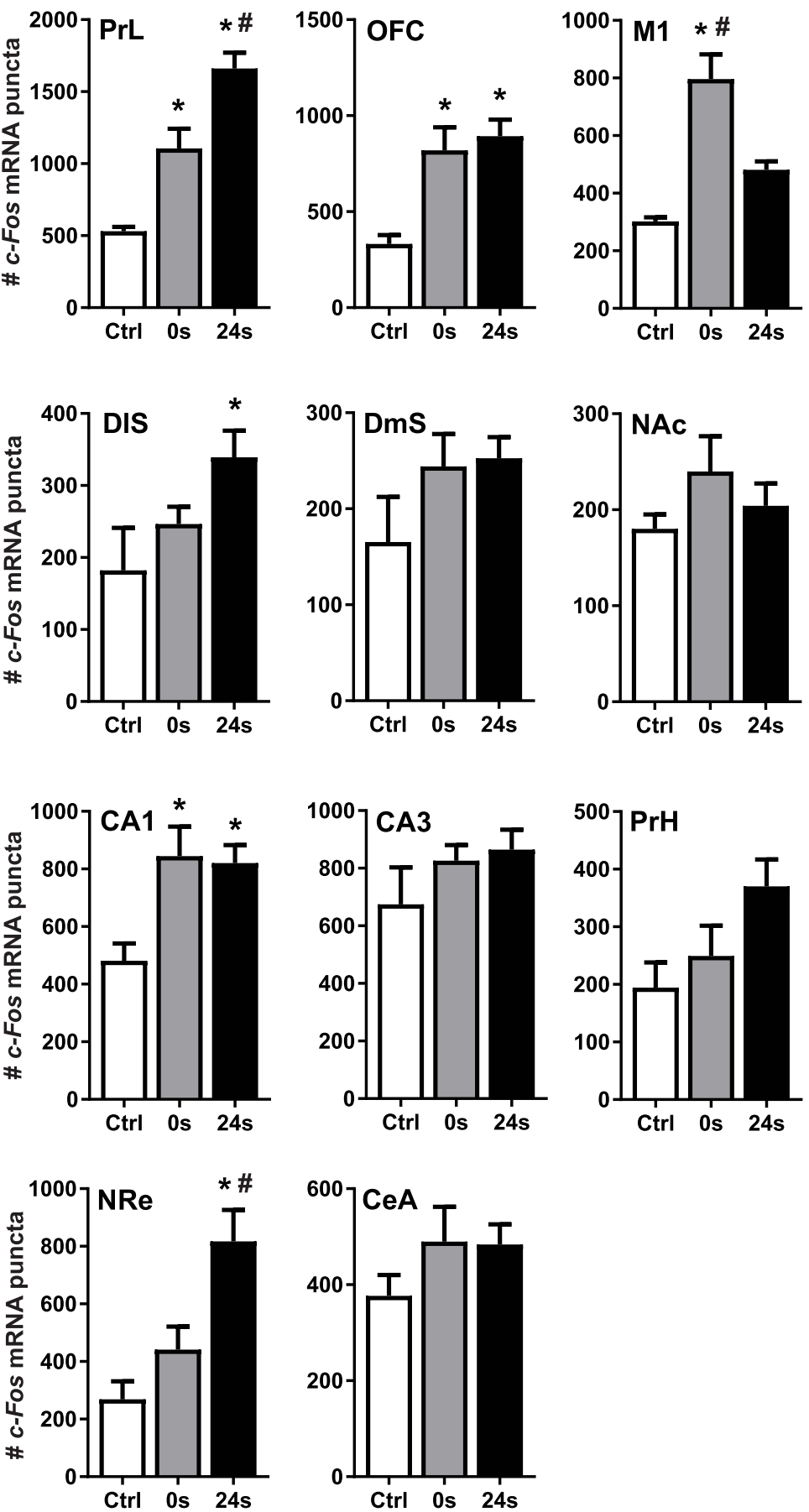

Figure 2. c-Fos mRNA expression after a DMS test with fixed 0- or 24-sec delays. (A-C, left) Rat brain coronal outlines according to (Paxinos and Watson 2005), with the brain areas used for the c-Fos mRNA analysis as highlighted. (A-C, middle and right) Quantitative analysis of $c$-Fos mRNA puncta within the outlined regions of interest corresponding to the prelimbic cortex (PrL), orbitofrontal cortex (OFC), primary motor cortex (M1), dorsolateral striatum (DIS), dorsomedial striatum (DmS), nucleus accumbens (NAc), CA1 and CA3 subregions of the hippocampus, perirhinal cortex (PrH), nucleus reuniens (NRe), and central amygdala $(\mathrm{CeA})$ in rats that underwent a single DMS test with fixed 0 - or $24-\mathrm{sec}$ delays, and in home-cage controls (Ctrl). Mean \pm SEM, $\left({ }^{*}\right) P<$ 0.05 versus $C$ trl group, (\#) $P<0.05$ versus 0 -sec delay group. $n=5-8 /$ group.

relevant, region-specific literature references. One-way ANOVAs were used to analyze between-group c-Fos mRNA levels (home cage controls, DMS test at 0 and $24 \mathrm{sec}$ ). Significant differences in $c$-Fos mRNA expression were found in the PrL $\left(F_{(2,17)}=23.10\right.$, $P<0.0001)$ (Fig. $2 \mathrm{~A}$, left), OFC $\left(F_{(2,16)}=6.89, P<0.01\right)$ (Fig. $2 \mathrm{~A}$, middle), $\mathrm{M} 1\left(F_{(2,16)}=15.45, P<0.001\right)$ (Fig. $2 \mathrm{~A}$, right), DIS $\left(F_{(2,16)}=4.12\right.$,
$P<0.05)$ (Fig. 2B, left), CA1 $\left(F_{(2,17)}=5.40, P<0.05\right)$ (Fig. 2C, left), and NRe $\left(F_{(2,16)}=7.90, P<0.01\right)$ (Fig. 2D, left). Tukey's multiple comparison tests were used for the follow-up analysis of all significant differences. Rats in the 24-sec condition expressed greater activation (number $c$-Fos mRNA puncta) in the PrL compared with rats in the 0 sec condition $(P<0.01)$ and home-cage controls $(P<$ 
$0.0001)$, and rats in the 0 -sec condition expressed more activation in the PrL compared with the home-cage controls $(P<0.05)$ (Fig. $2 \mathrm{~A}$, left). Compared with home-cage controls, rats in the 0 -sec $(P$ $<0.05)$, and 24 -sec conditions $(P<0.01)$ expressed greater activation (c-Fos mRNA puncta) in the OFC (Fig. 2A, middle). Rats in the 0 -sec condition showed greater activation in M1 compared with home-cage controls $(P<0.001)$ and rats in the 24 -sec condition $(P<0.01$, Fig. 2 A, right). Rats in the 24 -sec condition showed greater activation in the DIS compared with home-cage controls $(P<0.05)$ (Fig. 2B, left). Compared with home-cage controls, rats in the 0 -sec groups $(P<0.05)$, and 24 -sec conditions $(P<0.05)$ expressed greater activation in CA1 (Fig. 2C, left). Rats in the 24-sec condition expressed greater activation in the NRe compared with rats in the 0 -sec condition $(P<0.05)$ and home-cage controls $(P<$ 0.01) (Fig. 2D, right).

\section{Correlations between c-Fos mRNA expression and DMS performance at fixed delay test}

Bivariate Pearson correlations were conducted to assess the relationship between c-Fos mRNA expression (number of puncta) and high-load working memory performance (percentage correct during the fixed 24-sec condition). We found a negative correlation between total PrL c-Fos mRNA expression and performance at the 24 sec delay ( $r=-0.72, n=8, P<0.05$ ) (Fig. 3B, left). $c$-Fos mRNA expression within the OFC, DIS, NRe, CA1, and PrH did not correlate with the performance at the $24 \mathrm{sec}$ delay (Fig. 3B, middle, right; Fig. 3C).

\section{c-Fos mRNA expression in PrL mGlu5+ cells in relation to fixed delay test DMS performance}

The number of $c$-Fos mRNA puncta was averaged across all mGlu5 mRNA-expressing cells within the target ROI across two brain sections per rat. A one-way ANOVA was conducted to assess $c$-Fos mRNA expression within PrL mGlu5+ cells between groups and found a significant difference $\left(F_{(2,17)}=27.32, P<0.0001\right)$. Rats in the $24 \mathrm{sec}$ condition expressed greater activation (average \# $c$-Fos mRNA puncta) within PrL mGlu5-expressing cells compared with rats in the 0 -sec condition $(P<0.01)$ and home cage controls $(P<0.0001)$. Rats in the 0 -sec condition expressed greater activation in PrL mGlu5-expressing cells compared with the home-cage controls $(P<0.05)$ (Fig. 4B, left). Bivariate Pearson correlations were conducted between the average number of $c$-Fos mRNA puncta within mGlu5 expressing cells in the PrL and WM performance (percent correct) during the 0 - or 24-sec conditions. We found a negative correlation between average $c$-Fos expression within mGlu5-expressing cells and DMS performance in the 24-sec condition $(r=-0.79, \mathrm{n}=8, P<0.05)$ (Fig. $4 \mathrm{~B}$, middle) but not in the 0 -sec condition ( $r$ $=0.04$, n.s) (Fig. 4B, right).

\section{PKC activity and protein expression in the PrL after a fixed delay DMS \\ test}

B

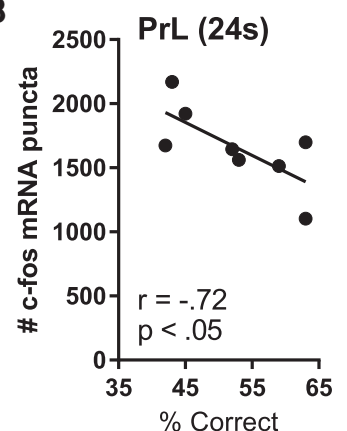

C

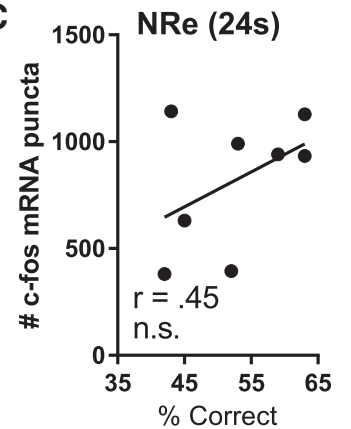

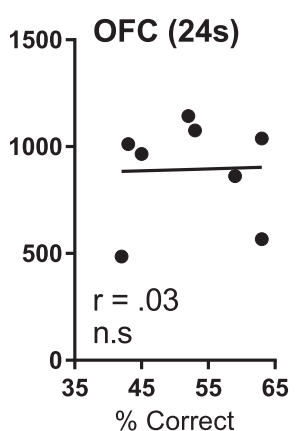

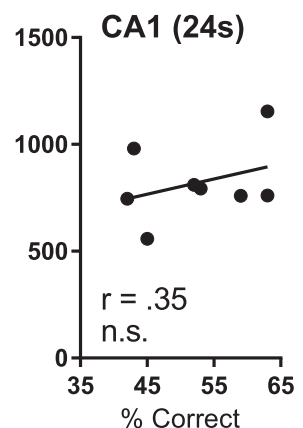

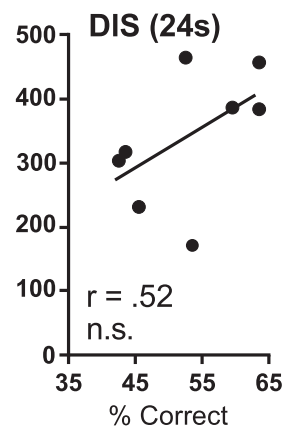

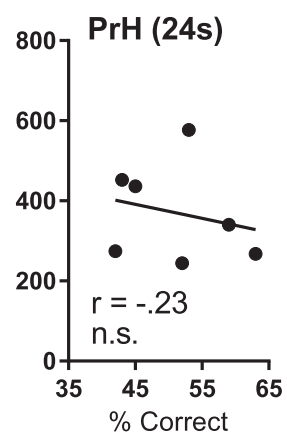

Figure 3. Correlation between c-Fos mRNA expression and DMS test performance under a fixed 24-sec delay conditions. $(A)$ Predicted neural connections between the brain regions analyzed. $(B, C)$ Correlation between the number c-Fos mRNA puncta in the PrL, OFC, DIS, NRe, CA1, and PrH, and DMS task performance (\% correct responses) under 24-sec delay condition. $n=7-8 /$ group.
To further explore possible neurobiological mechanisms recruited during the WM task in the PrL, PKC activity in this brain region was evaluated using the phospho-(Ser) PKC substrate antibody. This antibody selectively detects the phosphorylation state of PKC consensus sites on many cellular proteins, providing an indirect measure of tissue PKC activity (Kim et al. 2010; Bilodeau and Schwendt 2016; Chopra et al. 2018). Due to different signal intensity, PKC-phosphorylated proteins with molecular weight $>120 \mathrm{kDa}$ (high $\mathrm{kDa}$ ) were analyzed separately from the $<120-\mathrm{kDa}$ proteins (low $\mathrm{kDa}$ ). A oneway ANOVA revealed significant group differences in PKC activity (PKC substrate phosphorylation) for both high-kDA $\left(F_{(2,17)}=4.28, \quad P<0.05\right)$ and low-kDA $\left(F_{(2,17)}=4.01, P<0.05\right)$ groups of proteins (Fig. 5B, left and middle). Follow-up posthoc analysis showed increased PKC-mediated phosphorylation of high-kDA $(P<$ $0.05)$ and low-kDA $(P<0.05)$ substrates in the PrL of rats tested under 24-sec delay conditions. A trend in increased PKC phosphorylation of low-kDa substrates was observed at the 0 sec delay $(P=0.07$; 
A

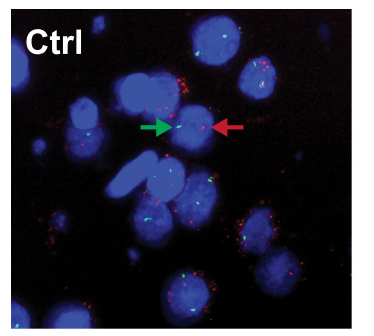

B

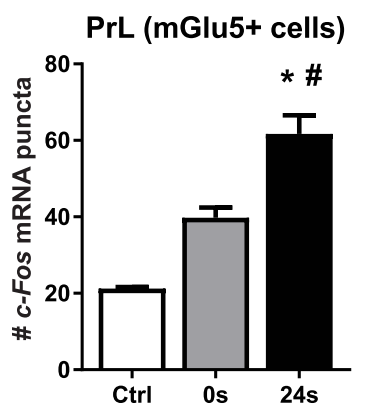

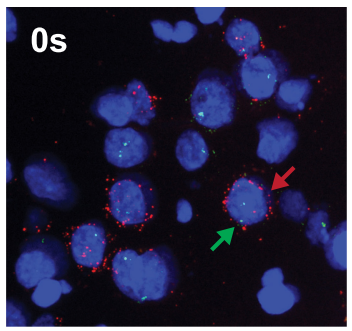

C

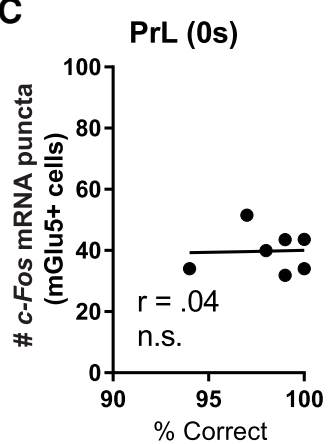

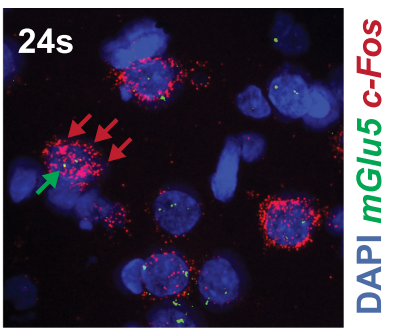

D

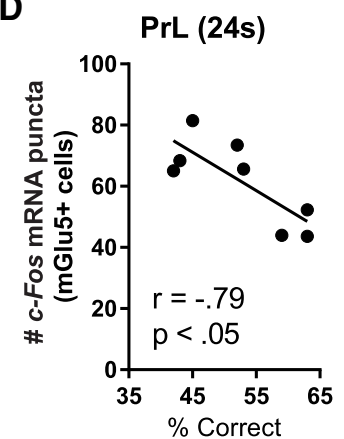

Figure 4. c-Fos mRNA expression in mGlu5+ cells in the PrL after a DMS test with fixed 0- and 24-sec delays. $(A)$ Representative images of c-Fos mRNA in mGlu5-expressing cells within the PrL for home-cage controls (left), rats in the 0 -sec condition (middle), and rats in the 24-sec condition (right). c-Fos mRNA and mGlu5 mRNA puncta are indicated in red and green, respectively. Nuclei are counterstained with DAPI (blue). (B) Quantitative analysis of the c-Fos mRNA puncta within the subpopulation of mGlu5+ cells in the PrL in control rats (Ctrl) and in rats that underwent a single DMS test under a fixed 0- or 24-sec conditions. $(C, D)$ Correlation between the number of $c$-Fos mRNA puncta and DMS task performance (\% correct) under a fixed 0 - or $24-s e c$ delay condition. Mean \pm SEM, $\left({ }^{*}\right) P<0.05$ versus Ctrl group, (\#) $P<0.05$ versus 0 -sec delay group. $n=5-8 /$ group. Original magnification, $40 \times$.

Fig. 5B). No relationship between the magnitude of PKC substrate phosphorylation in the PrL and high load working memory performance (percentage correct at the 24-sec delay condition) was found (data not shown). In contrast to varied PKC activity, no group differences in the overall PKC content in the PrL were found (Fig. 5B, right). The immunoblotting analysis also did not find group differences in c-Fos protein content (Fig. 5C) and mGlu5 dimer and monomer levels in the PrL (Fig. 5D, left and right). As the duration of the final DMS test (30 min) was too short to alter protein levels, these data indicate that there were no pre-existing group differences in c-Fos, mGlu5 or PKC protein content in the PrL.

\section{Discussion}

The current study characterizes $c$-Fos-expressing neuronal populations recruited with an increasing WM load in rats performing an operant DMS task. It identifies the PrL as the brain region, most sensitive to variations in WM load, with a broader circuitry that includes dorsolateral striatum (DIS), nucleus Reuniens (NRe), and the CA1 subregion of the hippocampus activated under low and/or high load conditions. On the other hand, neuronal activity detected in the primary motor cortex (M1) reflects motor activity, not the task difficulty. This study also found that under the conditions of high WM load, c-Fos mRNA levels in the PrL negatively correlate with the performance accuracy in the DMS task, suggesting inefficiency in neuronal processing. Initial exploration of the neural and molecular substrates activated with an increased WM load revealed that increasing WM load (1) up-regulates $c$-Fos expression in a subset of PrL neurons that also express mGlu5 and (2) is associated with hyperactivity of PKC, the main intracellular kinase associated with this receptor. This indicates that the PrL (and some other directly or indirectly connected brain areas) are recruited with increasing WM load and that the magnitude of mGlu5- and/or PKC-dependent signaling in this brain region predicts WM performance under these conditions. The present findings also complement our recent research showing that chronic cocaine impairs DMS task performance in rats, particularly under the increased WM load conditions, and that aberrant PrL activity (assessed via immediate-early gene expression) is related to both postcocaine WM deficits and persistent cocaine-seeking (Gobin et al. 2019; Hámor et al. 2020).

Here, we used an operant DMS task that allows for programmed, trial-by-trial changes in the task difficulty (delay) and thus it is suitable for the detailed analysis of animal behavioral performance in relation to WM load (see the last paragraph for more discussion on this topic). In our study, the choice accuracy (percent correct choices per session) ranged from $\sim 98 \%$ (at 0-sec delay) to 62\% (at 24-sec delay) during the baseline DMS testing. We also observed that the overall baseline DMS task performance is relatively stable in well-trained rats as no differences between testing Block 1 and 2 were detected. However, once the task parameters were altered in the final test (changed from a random presentation of seven different 0- to 24-sec delays to a fixed 0- or 24-sec delay), performance in the 24-sec group suffered and declined to near-chance levels. Rats in the 24-sec group also completed significantly fewer trials compared with their 0-sec counterparts. This is indicative of very demanding task conditions under which rats possibly experienced high reward-delivery uncertainty and "frustration" that is known to negatively affects WM performance in humans (Fillauer et al. 2020). Even though "frustration" is an anthropomorphic concept, some evidence suggests that the "frustration effect" can account for the altered strength of reinforced and nonreinforced responses in rats (Stout et al. 2003).

The main goal of this study was to follow-up on the WM performance data with an assessment of neural activity, measuring c-Fos mRNA expression. Specifically, we used this approach to quantify neural activity/c-Fos expression across a number of brain regions at the end of the single DMS test conducted under fixed 0 or $24 \mathrm{sec}$ delay conditions, corresponding to low and high WM load, respectively. Out of all brain regions analyzed, the PrL displayed a unique pattern of $c$-Fos mRNA expression that mirrored increasing WM load. This was a novel, though not surprising, finding, as the PrL is a key regulator of rodent WM (Vertes 2004; Arime and Akiyama 2017). Persistent firing and synchronization within PrL neurons have been identified during the delay period in a WM task and implicated in the encoding and representation of WM (Jung et al. 1998; Yang et al. 2014; Constantinidis et al. 2018). Consequently, acute inactivation, lesioning, or pathological changes within the PrL result in WM deficits (Izaki et al. 2001; Sloan et al. 2006; Arime and Akiyama 2017) and others. This is also true for the type of operant DMS task used in this study, as lesioning the mPFC (including the PrL) severely impairs WM performance in 
A
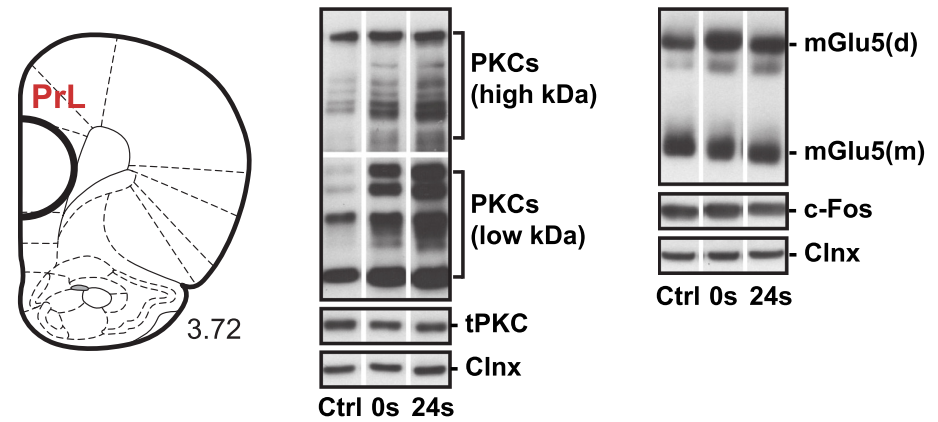

B
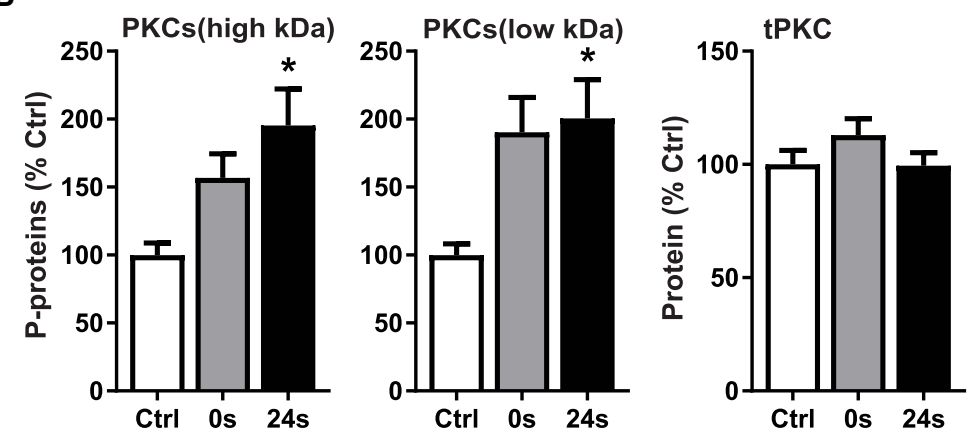

C
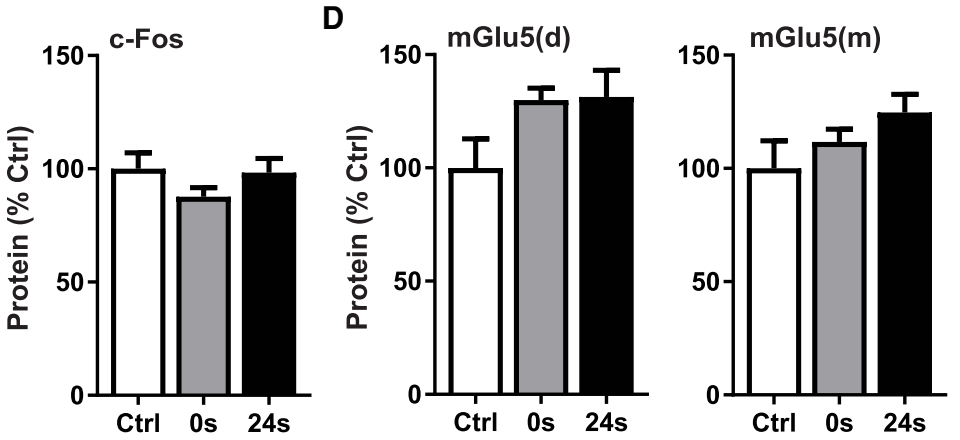

Figure 5. PKC activity and protein expression in the PrL after a DMS test with fixed 0 and 24 sec delays. (A) (left) A rat brain coronal outline according to (Paxinos and Watson 2005), with the PrL dissection site highlighted (right). Representative immunoreactive bands as detected with antibodies against phospho-(Ser) PKC substrates (PKCs), total PKC (tPKC), c-Fos protein, mGlu5 receptor (monomer and dimer), and loading control, calnexin (Clnx). Numbers to the left of each blot correspond to molecular weight of proteins in kilodaltons. $(B-D)$ Quantitative immunoblotting analysis of high/low-molecular weight phospho-PKC substrates and TPKC, c-Fos protein and mGlu5 monomer and dimer. Mean \pm SEM, $\left(^{*}\right) P<0.05$ versus Ctrl group. $n=5-8$ /group.

this task (Sloan et al. 2006). Interestingly, mPFC lesions did not impair the ability to adapt to rule switching (from match-to-sample to non-match-to-sample) (Sloan et al. 2006), indicating that other brain regions (such as the OFC) (discussed below) mediate cognitive flexibility in this task.

Beyond the PrL, two other cortical areas analyzed also showed altered $c$-Fos mRNA levels after the final DMS test. In the OFC, increased $c$-Fos mRNA levels were detected in all rats exposed to the final DMS test regardless of the delay used. This finding is in agreement with the OFC-centric circuits controlling cognitive flexibility, rather than WM performance (Barbey et al. 2011; Fettes et al. 2017). It could be hypothesized that switching from a variable 0 - to 24-sec delay to a fixed (0- or 24-sec) delay, calls for an update in the learned behavioral strategies, which in turn requires bringing the OFC online. Accordingly, activation of this brain region oc- curs in response to changes in the DMS task parameters (from variable to fixed delay, both DMS groups), not increased task difficulty (delay, 24-sec group only). Research in human subjects suggests that the OFC is involved in the coordination of multiple WM processes in situations when the application of prior cognitive strategies is not sufficient to achieve a behavioral goal. In support, patients with damage to the OFC display deficits in complex tasks that require coordination of WM maintenance, manipulation, and monitoring processes, but not in simple tests of WM maintenance (Barbey et al. 2011). In contrast to both the PrL and the OFC regions, $c$-Fos expression in the primary motor cortex (M1) reflected recent motor activity, with rats in the 0 sec test group showing significantly up-regulated c-Fos mRNA and the most trials completed, in comparison with the 24-sec group (fewer trials completed) or home cage controls (rest, no trials).

We have also evaluated a number of subcortical regions. In the striatum, increased $c$-Fos mRNA levels were detected in the DIS under the $24 \mathrm{sec}$ delay conditions, but not in the DmS or NAc. The lack of $c$-Fos changes in the DmS was somewhat surprising, as prior studies have indicated the involvement of this brain region in controlling the choice accuracy in operant and T-maze-based delayed nonmatch to position (DNMTP) tasks (Akhlaghpour et al. 2016; Li et al. 2018). It should be noted that our results do not rule out the role for cortico-striatal projections in WM performance; instead, they suggest that depending on task rules (DMS vs. DNMTP; novel vs. well-trained), or altered frequency of reward delivery, the cortico-striatal map might include the DIS not DmS (Balleine et al. 2007). Alternatively, as firing pattern in the DmS is transient and shifts throughout the delay period (unlike the persistent firing of the delay cells in the PrL) (Akhlaghpour et al. 2016), DmS neuronal activity might not be sufficient to generate measurable differences in c-Fos mRNA levels.

The midline thalamic nucleus termed the NRe has been assigned the role of an important brain structure supporting reciprocal hippocampal-mPFC communication. It is believed that the NRe relays and regulates spatial and contextual information between these brain structures, contributing to the synchronized firing of the MPFC and hippocampus under conditions of increased WM load (for reviews, see Griffin 2015; Dolleman-van der Weel et al. 2019). In agreement, our data confirm a delay-dependent activation of the NRe (increased c-Fos mRNA levels in the $24 \mathrm{sec}$ delay group). This suggests that the NRe is recruited even during WM tasks with a lesser spatial component, as compared with spatial WM tasks, such as a delayed alternation task in a T-maze (Viena et al. 2018). The NRe neurons that receive input from the mPFC send dense excitatory projections to the CA1 subregion of the dorsal hippocampus (Herkenham 1978; Wouterlood et al. 1990). It is 
this projection that is responsible for the synchronous corticohippocampal activity during memory processing and consolidation (Hauer et al. 2019). Here, we found an increase in c-Fos mRNA levels in the CA1 (but not in the CA3) subregion of rats after the final DMS test, regardless of the length of the delay imposed. It is possible that in addition to the PrL, other cortical regions (perhaps the OFC) interact with the CA1 to offer behavioral flexibility under changed experimental conditions, such as when variable delay testing is replaced by the single delay in the final DMS test. Even though not well understood, the interactions between the OFC and the hippocampus is thought to promote cognitive flexibility during learning, memory, and decision making (Wikenheiser and Schoenbaum 2016), suggesting that the analogous pattern of c-Fos mRNA up-regulation detected in the OFC and the CA1 is not accidental. The role of CA1 in supporting continuous DMS task performance should be further evaluated, as studies disagree whether the global hippocampal lesions impair WM in operant DMS/DNMS tasks (Aggleton et al. 1992; Broersen 2000; Sloan et al. 2006). To broaden the interpretation of the CA1 c-Fos data, we analyzed neuronal activity related to the recent DMS task performance in the PrH. The PrH is a cortical region that has robust reciprocal connections with the hippocampal formation, in particular with the CA1 subregion of the hippocampus (Kealy and Commins 2011). By controlling the information flow into and out of the CA1, the PrH has been shown to participate in cognitive processes, such as object- or stimulus-recognition memory (Lee and Park 2013). However, limited evidence suggests that selective lesions of the PrH produced deficits in an operant delayed non-matching-to-position task in rats, that were more pronounced at longer delays (Wiig and Bilkey 1994; Wiig and Burwell 1998). Here, we failed to find a significant up-regulation of $c$-Fos mRNA in the $\mathrm{PrH}$, though a trend toward an increase was detected at the longer $24 \mathrm{sec}$ delay. Finally, to assess the specificity of the observed patterns of neuronal activation for the DMS task, we evaluated $c$-Fos mRNA in the CeA, a brain nucleus linked to long-term emotional memory, but not necessary for immediate WM (Bianchin et al. 1999). In agreement, we found no differences in $c$-Fos mRNA in the CeA.

Beyond uncovering region-specific and demand-dependent differences in neuronal activation during WM testing, we sought to investigate the relationship between choice accuracy (percent correct responses) and c-Fos mRNA levels. Out of the six brain regions in which c-Fos mRNA was elevated under the high load (24-sec delay condition), only the PrL c-Fos levels correlated with choice accuracy. As discussed above, a switch from the variable 0 to 24-sec delay set (baseline testing) to a forced 24-sec delay in the final DMS test, increased task difficulty. It is possible that the observed negative correlation between the PrL c-Fos levels and high load WM performance reflects (1) recruitment of additional network capacity within the PrL to support new learning required to improve task performance and increase the frequency of reward delivery, or (2) it is a nonspecific up-regulation of the PrL activity due to a "frustration effect" related to an inability to receive reward.

Since the PrL activity showed the highest sensitivity to WM load, this study set out to further characterize neural and molecular substrates within this brain region activated during WM testing. While the neural mechanisms of WM are complex (for reviews, see Goldman-Rakic 1995; Arnsten and Jin 2014), studies in humans and animals suggest that glutamatergic activity in the PrL (or dIPFC) is necessary for "normal" WM performance. In this regard, a recent study by Woodcock et al. (2018) showed that glutamate levels rise in the human dIPFC in response to increased WM demand. On the other hand, inhibiting glutamate release via local administration of mGlu2/3 (auto)receptor agonists, or blockade of the postsynaptic ionotropic glutamate receptors disrupted sustained firing of local pyramidal neurons and impaired WM perfor- mance in animals (Gregory et al. 2003; Wang et al. 2013; van Vugt et al. 2020). Recent studies by our laboratory and others, showed that systemic or local intra-PrL inhibition of mGlu5 receptors impairs DMS task performance (Hernandez et al. 2018; Gobin and Schwendt 2020; Hámor et al. 2020). This study reveals for the first time that increasing WM demand progressively recruits mGlu5-positive cells in the PrL as evidenced by increased c-Fos/ mGlu5+ mRNA in the 24-sec (but not in the 0-sec) delay group. Similar to overall c-Fos expression, c-Fos/mGlu5+ expression in the PrL negatively correlates with choice accuracy, suggesting that activity within this neuronal subpopulation serves to compensate or overcome behavioral inefficiency.

Additionally, as PKC is the major cellular effector downstream from mGlu5 receptors implicated in WM (Birnbaum et al. 2004; Runyan et al. 2005; Dash et al. 2007), this study analyzed whether the activity of this kinase in the PrL tracks increased WM load (delay). The phosphorylation status of peptide sequences selectively recognized by the PKC served as a measure of PKC-mediated cellular phosphorylation, and ultimately, as an accurate indicator of PKC tissue activity (Kim et al. 2010; Bilodeau and Schwendt 2016; Chopra et al. 2018). We found that phosphorylation of both high- and low-molecular-weight PKC substrates was increased in the $24 \mathrm{sec}$ delay group. This corresponds with findings of increased PKC activity in the mPFC of unimpaired rats immediately after a delayed-match-to-place test in a Morris water maze (Runyan et al. 2005). As PKC is crucial for memory formation in many other brain regions (for review, see Sun and Alkon 2014), the question arises, whether the observed increase in the PrL PKC activity is promoting, or degrading WM. Previously, excessive activation of PKC in the mPFC has coincided with the stress-induced disruption of WM, while in aged rats, PKC activity predicted WM impairment (Birnbaum et al. 2004; Brennan et al. 2009). And further, systemic or intra-PFC inhibition of PKC improved WM performance in normal young rats, or rescued stressor aging-related WM impairment (Birnbaum et al. 2004; Brennan et al. 2009; Hains et al. 2009). The molecular mechanism of how abnormal PKC activity disrupts WM performance is not clear, though it can include interference with the delay-related activity of the dedicated pyramidal neurons (Birnbaum et al. 2004). This can explain how elevated PKC in the 24-sec delay group can contribute to poor WM performance observed in our study. However, as WM requires "optimal" cognitive processing, and both hypofunction or hyperactivity of delay cells can negatively affect WM, future studies should investigate the possibility that the relationship between PKC activity and WM is more complex, perhaps following an inverted U-shape curve, akin to the effects of increasing dopaminergic and glutamatergic tone in the PFC on WM (Vijayraghavan et al. 2007; Cools and D'Esposito 2011; Jin et al. 2017).

Finally, it should be noted that in the current study, we assessed neural activity (c-Fos mRNA) that likely reflected recent overall task performance, rather than rapid changes in neuronal activity during individual phases of the DMS task. We have also limited our tissue analysis to the extreme endpoints of the DMS task performance curve and maintained the delays constant throughout the final test. While maintaining constant delays was a necessary prerequisite to study the relationship between c-Fos expression and behavior, it is possible the including a third condition (a mid-range delay of 8 or $12 \mathrm{sec}$ ) would have uncovered neural activity in additional brain regions, or provided more information on the relationship between $c$-Fos levels and the task performance. In this regard, a recent study using a head-fixed variation of the DMS task in mice revealed that neuronal activity in the mPFC is influenced by the predictability of delay duration (Park et al. 2019). This study also showed that subsets of neurons within this brain region display dynamic patterns of activity 
over the course of the delay, with some neurons increasing their activity immediately at the conclusion of the sample phase, while other neurons "waited" and were only activated later during the ongoing delay in the choice phase. Therefore, we hypothesize that even under no-delay conditions (0 sec group), neurons relevant for the WM performance are already being recruited, reflecting (albeit low) WM load that is later followed by $c$-Fos activation. Future studies should incorporate some of these variables into their design to explore the temporal nature of WM processes in various brain circuits.

\section{Materials and Methods}

\section{Animals}

Adult male Sprague-Dawley rats (Charles River Laboratories; $275 \mathrm{~g}$ on arrival; $N=20$ ) were first acclimated to the animal facility prior to any manipulation. They were housed individually, maintained on a $12 \mathrm{~h}$ reverse light-dark cycle (lights off at 0700 ), and given ad libitum access to water, and food-restricted (15-20 g of food per day) to maintain $\sim 85 \%$ of their free-feeding weight as previously described (Gobin and Schwendt 2017; Gobin et al. 2019). All animal procedures were approved by the Institutional Animal Care and Use Committee of the University of Florida and performed in accordance with the Guide for the Care and Use of Laboratory Animals. The overall experimental timeline is depicted in Figure $1 \mathrm{~A}$.

\section{Operant delayed match-to-sample task: training and testing under a variable delay condition}

Rats were trained and tested in the delayed match-to-sample (DMS) task, as previously described (Gobin et al. 2019). Briefly, rats were subjected to daily $40 \mathrm{~min}$ training (or testing) sessions (one session per day) in standard rat operant chambers $(30 \times 24 \times$ $30 \mathrm{~cm}$; Med Associates) equipped with two levers. Each session began with an illumination of the house light, which remained on throughout the session, except during time-outs. Each trial consisted of three phases: a sample phase, a delay period, and a choice phase. In the sample phase, a left or right lever was randomly selected by the computer such that there was equal presentation of each lever throughout the session. Pressing the sample lever resulted in retraction of that lever, delivery of a sucrose pellet, and initiation of the delay interval with randomized delay durations. During the choice phase, both levers were presented for $10 \mathrm{sec}$ before they retracted, and no-response event was recorded as an omission. Pressing the lever previously presented during the sample phase resulted in delivery of a sucrose pellet and the correct response was recorded. Pressing the other lever was scored as an incorrect response and resulted in a time-out period wherein no sucrose pellet was delivered, the house light was extinguished, and both levers were retracted for a duration of $6 \mathrm{sec}$ prior to the start of the next trial (time-out period). First, rats underwent a 30 min magazine training session wherein 29 sucrose pellets were delivered into the food hopper at random intervals, and rats were required to consume all of these pellets prior to progressing to lever press shaping. During lever press shaping, rats were presented with only the left lever in a 60-min session. Upon reaching a criterion of at least 50 lever presses on the left lever (each rewarded with a sucrose pellet), they underwent lever press shaping for the right lever the following day with the same criterion. During the next training phase, rats were trained without any delays between the sample and choice phase, including a correction procedure to prevent the development of side biases. Next, rats were trained at two delay sets: short delay set $\{0,1,2,3,4,5,6 \mathrm{sec}\}$, and intermediate delay set $\{0,2,4,8,12,16 \mathrm{sec}\}$. Rats were required to reach a criterion of $\geq 80 \%$ correct responses over two consecutive days prior to progressing to the next delay set. Finally, upon reaching criterion at the intermediate training delay set, rats entered the testing phase for two blocks of $5 \mathrm{~d}$ at the final delay set $\{0,2,4$, $8,12,18,24 \mathrm{sec}\}$.

\section{Operant delayed match-to-sample task: the final test under a fixed delay condition}

Following the completion of the two DMS testing blocks, rats were assigned to either 0- or 24-sec test (or home cage control) conditions and subjected to a final DMS test. This test was modified to last $30 \mathrm{~min}$ (corresponding to a peak in stimulus-induced $c$-Fos response; Gallo et al. 2018), and each trial was limited to a presentation of a single delay ( 0 or $24 \mathrm{sec}$ ) to test DMS performance under low-load (easy), or high-load (hard) WM conditions $(n=7-8$ / group). Control rats $(n=5)$ were handled but remained in their home cage.

\section{Tissue collection and processing}

Rats were euthanized by decapitation immediately following the final DMS test (or after their removal from the home cage). Rat brains were rapidly extracted, left and right hemispheres separated, and snap-frozen in isopentane (2-methylbutane) chilled on dry ice. The right hemisphere was cut into serial $12-\mu \mathrm{m}$ coronal brain sections using a cryostat (Leica CM1950). Tissue sections were collected as follows: PrL, M1, and OFC were collected approximately at +3.72 , DlS, DmS, and NAc were collected at approximately +1.56 , while sections containing CA1, CA3, PrH, CeA, and NRe were collected approximately at -3.12 relative to Bregma (Paxinos and Watson 2005). Sections were freeze-mounted onto Superfrost Plus Gold slides (Fisher Scientific), air-dried, and stored at $-80^{\circ} \mathrm{C}$. The PrL tissue from the left hemisphere was collected using a 2-mm micropunch (Harris Uni-Core, Ted Pella), as shown in Figure $5 \mathrm{~A}$. All tissues were stored at $-80^{\circ} \mathrm{C}$ for later fluorescent in situ hybridization (right hemisphere sections), or Western blotting analysis (left hemisphere PrL punches).

\section{Fluorescent in situ hybridization}

Fluorescent in situ hybridization (FISH) for c-Fos and $m$ Glu 5 (Grm5) mRNAs was performed using standard or custom-designed validated target riboprobes (Gobin et al. 2019), ACDBio and RNAscope Multiplex Fluorescent Reagent Kit (ACDBio) following published procedures (Wang et al. 2012; Gobin et al. 2019). Briefly, rat brain sections were fixed in $4 \%$ paraformaldehyde (PFA) for $15 \mathrm{~min}$ at $4^{\circ} \mathrm{C}$, dehydrated in a series of graded $\mathrm{EtOH}$ concentrations for 5 min each $(50 \%, 70 \%, 100 \%, 100 \%)$ and dried at room temperature prior to undergoing 25-min protease digestion using pretreatment \#4 (ACDBio). RNAscope target probes for c-Fos (ACDBio 403591-C1, lot 18179C) and mGlu5 (GRM5; ACDBio 471241-C2, lot 17243B) were applied to each section, and slides were incubated at $40^{\circ} \mathrm{C}$ for $2 \mathrm{~h}$. Next, preamplifier and amplifier probes were applied to each section and incubated at $40^{\circ} \mathrm{C}$ (AMP 1, $30 \mathrm{~min}$; AMP 2, $15 \mathrm{~min}$; AMP 3, $30 \mathrm{~min}$ ). The AMP 4 Alt-C was selected so that $c$-Fos and mGlu5 probes were labeled with ATTO 550 and Alexa 647 fluorophores, respectively. Sections were counterstained with DAPI and coverslipped with ProLong Gold antifade mounting reagent (Thermo Fisher). Fluorescent images were obtained using an Olympus BX51 microscope equipped with an apochromatic $40 \times$ objective, CCD high-resolution camera, and ISIcapture software (both by Tucsen Photonics). Quantification of mRNA puncta was performed in Image J and MATLAB (Mathworks) using TransQuant software (Bahar Halpern and Itzkovitz 2016). Cells expressing both c-Fos and mGlu5 mRNA transcripts were identified manually with ImageJ (Schneider et al. 2012). Segmentation of all dual c-Fos/mGlu5-positive cells was performed in TransQuant and within-cell $c$-Fos mRNA puncta were measured.

\section{Immunoblotting}

The tissue protein lysates were prepared from the PrL as described previously (Bilodeau and Schwendt 2016). Total protein content was quantified using bicinchoninic acid (BCA) assay according to the manufacturer's instructions (BCA Protein Assay Kit, Thermo Fisher). Equal amounts of total protein $(15 \mu \mathrm{g} /$ lane) were separated by SDS-PAGE (4\%-15\% polyacrylamide) and transferred onto polyvinylidene difluoride (PVDF) membranes. Membranes were blocked for $1 \mathrm{~h}$ in $5 \%$ milk in Tris-buffered saline buffer that 
included $0.1 \%$ Tween 20 (TBST), and probed overnight with the following primary antibodies: rabbit anti-phospho-(Ser) PKC substrates (1:15,000; Cell Signaling 2261), mouse anti-pan PKC (1:10,000, MilliporeSigma 05-983), rabbit anti-c-FOS (1:10,000; MilliporeSigma ABE457), and rabbit anti-mGlu5 (1:5000; MilliporeSigma AB5675). PKC substrate antibody selectively detects proteins with phosphorylated PKC consensus sites (phosphorylated Ser residues surrounded by Arg or Lys at the -2 and +2 positions and a hydrophobic residue at the +1 position, Cell Signaling). Next, membranes were washed three times in 5\% milk/TBST and incubated with a species-matched HRP-conjugated secondary antibody (1:20,000, Jackson Immuno Research). Immunoreactive bands on the membranes were visualized with a chemiluminescent reagent $(\mathrm{ECL}+)$ using a high performance chemiluminescence film (both from GE Healthcare). Equal loading and transfer of proteins was verified with a reversible protein stain (Ponceaus $S$ ) and by reprobing membranes with a housekeeping protein calnexin (1:20,000, ADI-SPA-860, Enzo Life Sciences). Integrated band density of each protein sample was measured using Image Studio Lite software (LI-COR Biosciences), normalized it to its respective calnexin integrated density measure, and expressed as the percentage of home-cage controls values.

\section{Statistical analysis}

GraphPad Prism (Version 8.4.2) software was used to analyze all data with the alpha level set at 0.05 for all statistical analyses. Repeated measures two-way ANOVA was used to compare withinsubject variables (Delay and Block) during DMS testing. One-way ANOVAs and $t$-tests were used to compare group differences on single dependent measures, wherever appropriate. Tukey's multiple comparison tests were used throughout the study to follow up significant effects. Two-tailed Pearson correlations were conducted to compare continuous variables.

\section{Acknowledgments}

We thank Dr. Jennifer Bizon and Dr. Joseph McQuail for their input on the design of the DMS task, as well as Peter Hámor and Lori Knackstedt for their valuable comments on the manuscript. We also thank Mr. Spencer Berman, Mr. James Hickman, and Mr. Jason Dee for their assistance with behavioral studies. This research was supported by the University of Florida McKnight Brain Institute Pilot Grant awarded to M.S.

\section{References}

Aggleton JP, Keith AB, Rawlins JNP, Hunt PR, Sahgal A. 1992. Removal of the hippocampus and transection of the fornix produce comparable deficits on delayed non-matching to position by rats. Behav Brain Res 52: 61-71. doi:10.1016/S0166-4328(05)80325-0

Akhlaghpour H, Wiskerke J, Choi JY, Taliaferro JP, Au J, Witten IB. 2016. Dissociated sequential activity and stimulus encoding in the dorsomedial striatum during spatial working memory. Elife 5: e19507. doi:10.7554/eLife.19507

Arime Y, Akiyama K. 2017. Abnormal neural activation patterns underlying working memory impairment in chronic phencyclidine-treated mice. PLoS One 12: e189287. doi:10.1371/journal.pone.0189287

Arnsten AFT, Jin LE. 2014. Molecular influences on working memory circuits in dorsolateral prefrontal cortex. Prog Mol Biol Transl Sci 122: 211-231. doi:10.1016/B978-0-12-420170-5.00008-8

Baddeley A. 1992. Working memory. Science 255: 556-559. doi:10.1126/ science.1736359

Bahar Halpern K, Itzkovitz S. 2016. Single molecule approaches for quantifying transcription and degradation rates in intact mammalian tissues. Methods 98: 134-142. doi:10.1016/j.ymeth.2015.11.015

Balleine BW, Delgado MR, Hikosaka O. 2007. The role of the dorsal striatum in reward and decision-making. J Neurosci 27: 8161-8165. doi:10.1523/ JNEUROSCI.1554-07.2007

Barbey AK, Koenigs M, Grafman J. 2011. Orbitofrontal contributions to human working memory. Cereb Cortex 21: 789-795. doi:10.1093/cercor/ bhq153

Bianchin M, Mello E Souza T, Medina JH, Izquierdo I. 1999. The amygdala is involved in the modulation of long-term memory, but not in working or short-term memory. Neurobiol Learn Mem 71: 127-131. doi:10.1006/ nlme.1998.3881
Bilodeau J, Schwendt M. 2016. Post-cocaine changes in regulator of G-protein signaling (RGS) proteins in the dorsal striatum: relevance for cocaine-seeking and protein kinase C-mediated phosphorylation. Synapse 70: 432-440. doi:10.1002/syn.21917

Bimonte HA, Nelson ME, Granholm AC. 2003. Age-related deficits as working memory load increases: relationships with growth factors. Neurobiol Aging 24: 37-48. doi:10.1016/S0197-4580(02)00015-5

Birnbaum SG, Yuan PX, Wang M, Vijayraghavan S, Bloom AK, Davis DJ, Gobeske KT, Sweatt JD, Manji HK, Arnsten AFT. 2004. Protein kinase C overactivity impairs prefrontal cortical regulation of working memory. Science 306: 882-884. doi:10.1126/science. 1100021

Bizon JL, Foster TC, Alexander GE, Glisky EL. 2012. Characterizing cognitive aging of working memory and executive function in animal models. Front Aging Neurosci 4: 19. doi:10.3389/fnagi.2012.00019

Bratch A, Kann S, Cain JA, Odineal DD, Deacy TK, Stein MTO, Colombo RE, Colombo CJ. 2016. Working memory systems in the rat. Curr Biol 26: 351-355. doi:10.1016/i.cub.2015.11.068

Braver TS, Cohen JD, Nystrom LE, Jonides J, Smith EE, Noll DC. 1997. A parametric study of prefrontal cortex involvement in human working memory. Neuroimage 5: 49-62. doi:10.1006/nimg.1996.0247

Brennan AR, Yuan P, Dickstein DL, Rocher AB, Hof PR, Manji H, Arnsten AFT. 2009. Protein kinase $C$ activity is associated with prefrontal cortical decline in aging. Neurobiol Aging 30: 782-792. doi:10.1016/j .neurobiolaging.2007.08.020

Broersen LM. 2000. Attentional processes and learning and memory in rats: the prefrontal cortex and hippocampus compared. Prog Brain Res 126: 79-94. doi:10.1016/S0079-6123(00)26008-1

Brown VJ, Bowman EM. 2002. Rodent models of prefrontal cortical function. Trends Neurosci 25: 340-343. doi:10.1016/S0166-2236(02) 02164-1

Brzezicka A, Kamiński J, Reed CM, Chung JM, Mamelak AN, Rutishauser U. 2018. Working memory load-related theta power decreases in dorsolateral prefrontal cortex predict individual differences in performance. J Cogn Neurosci 31: 1290-1307. doi:10.1162/ jocn_a_01417

Chai WJ, Abd Hamid AI, Abdullah JM. 2018. Working memory from the psychological and neurosciences perspectives: a review. Front Psychol 9: 401. doi:10.3389/fpsyg.2018.00401

Chen SHA, Desmond JE. 2005. Temporal dynamics of cerebro-cerebellar network recruitment during a cognitive task. Neuropsychologia 43: 12271237. doi:10.1016/j.neuropsychologia.2004.12.015

Chopra R, Wasserman AH, Pulst SM, De Zeeuw CI, Shakkottai VG. 2018. Protein kinase $\mathrm{C}$ activity is a protective modifier of Purkinje neuron degeneration in cerebellar ataxia. Hum Mol Genet 27: 1396-1410. doi:10 $.1093 / \mathrm{hmg} / \mathrm{ddy} 050$

Constantinidis C, Funahashi S, Lee D, Murray JD, Qi XL, Wang M, Arnsten AFT. 2018. Persistent spiking activity underlies working memory. J Neurosci 38: 7020-7028. doi:10.1523/JNEUROSCI.2486-17 .2018

Cools R, D'Esposito M. 2011. Inverted-U-shaped dopamine actions on human working memory and cognitive control. Biol Psychiatry 69: e113-e125. doi:10.1016/j.biopsych.2011.03.028

Daniel TA, Katz JS, Robinson JL. 2016. Delayed match-to-sample in working memory: a BrainMap meta-analysis. Biol Psychol 120: 10-20. doi:10 $.1016 /$ j.biopsycho.2016.07.015

Dash PK, Moore AN, Kobori N, Runyan JD. 2007. Molecular activity underlying working memory. Learn Mem 14: 554-563. doi:10.1101/lm .558707

Dolleman-van der Weel MJ, Griffin AL, Ito HT, Shapiro ML, Witter MP, Vertes RP, Allen TA. 2019. The nucleus reuniens of the thalamus sits at the nexus of a hippocampus and medial prefrontal cortex circuit enabling memory and behavior. Learn Mem 26: 191-205. doi:10.1101/ $\operatorname{lm} .048389 .118$

Dosher BA. 2006. Working memory. In: Encyclopedia of cognitive science (ed. Nadel L), pp. 1-9. John Wiley \& Sons, New York. doi:10.1002/ $0470018860 . s 00575$

Fettes P, Schulze L, Downar J. 2017. Cortico-striatal-thalamic loop circuits of the orbitofrontal cortex: promising therapeutic targets in psychiatric illness. Front Syst Neurosci 11: 25. doi:10.3389/fnsys.2017.00025

Fillauer JP, Bolden J, Jacobson M, Partlow BH, Benavides A, Shultz JN. 2020. Examining the effects of frustration on working memory capacity. Appl Cogn Psychol 34: 50-63. doi:10.1002/acp.3587

Gallo FT, Katche C, Morici JF, Medina JH, Weisstaub NV. 2018. Immediate early genes, memory and psychiatric disorders: focus on c-Fos, Egr1 and Arc. Front Behav Neurosci 12: 79. doi:10.3389/fnbeh.2018.00079

George O, Mandyam CD, Wee S, Koob GF. 2008. Extended access to cocaine self-administration produces long-lasting prefrontal cortex-dependent working memory impairments. Neuropsychopharmacology 33: 24742482. doi:10.1038/sj.npp.1301626

Gobin C, Schwendt M. 2017. The effects of extended-access cocaine self-administration on working memory performance, reversal learning 
and incubation of cocaine-seeking in adult male rats. J Addict Prev 5: $10.13188 / 2330-2178.1000035$.

Gobin C, Schwendt M. 2020. The cognitive cost of reducing relapse to cocaine-seeking with mGlu5 allosteric modulators. Psychopharmacology (Berl) 237: 115-125. doi:10.1007/s00213-019-05351-8

Gobin C, Shallcross J, Schwendt M. 2019. Neurobiological substrates of persistent working memory deficits and cocaine-seeking in the prelimbic cortex of rats with a history of extended access to cocaine self-administration. Neurobiol Learn Mem 161: 92-105. doi:10.1016/j .nlm.2019.03.007

Goldman-Rakic PS. 1995. Cellular basis of working memory. Neuron 14: 477-485. doi:10.1016/0896-6273(95)90304-6

Gregory ML, Stech NE, Owens RW, Kalivas PW. 2003. Prefrontal group II metabotropic glutamate receptor activation decreases performance on a working memory task. Ann N Y Acad Sci 1003: 405-409. doi:10.1196/ annals. 1300.037

Griffin AL. 2015. Role of the thalamic nucleus reunions in mediating interactions between the hippocampus and medial prefrontal cortex during spatial working memory. Front Syst Neurosci 9: 29. doi:10.3389/ fnsys.2015.00029

Hains AB, Vu MAT, Maciejewski PK, van Dyck CH, Gottron M, Arnsten AFT. 2009. Inhibition of protein kinase $C$ signaling protects prefrontal cortex dendritic spines and cognition from the effects of chronic stress. Proc Natl Acad Sci 106: 17957-17962. doi:10.1073/pnas.0908563106

Hámor PU, Gobin CM, Schwendt M. 2020. The role of glutamate mGlu5 and adenosine A2a receptor interactions in regulating working memory performance and persistent cocaine seeking in rats. Prog Neuro Psychopharmacol Biol Psychiatry 103: 109979. doi:10.1016/j.pnpbp.2020 .109979

Hauer BE, Pagliardini S, Dickson CT. 2019. The reuniens nucleus of the thalamus has an essential role in coordinating slow-wave activity between neocortex and hippocampus. eNeuro 6: ENEURO.0365-19.2019. doi:10.1523/ENEURO.0365-19.2019

Herkenham M. 1978. The connections of the nucleus reuniens thalami: evidence for a direct thalamo-hippocampal pathway in the rat. J Comp Neurol 177: 589-609. doi:10.1002/cne.901770405

Hernandez CM, McQuail JA, Schwabe MR, Burke SN, Setlow B, Bizon JL. 2018. . Age-related declines in prefrontal cortical expression of metabotropic glutamate receptors that support working memory. eNeuro 5: ENEURO.0164-18.2018. doi:10.1523/ENEURO.0164-18.2018

Horst NK, Laubach M. 2009. The role of rat dorsomedial prefrontal cortex in spatial working memory. Neuroscience 164: 444-456. doi:10.1016/j .neuroscience.2009.08.004

Izaki Y, Maruki K, Hori K, Nomura M. 2001. Effects of rat medial prefrontal cortex temporal inactivation on a delayed alternation task. Neurosci Lett 315: $129-132$. doi:10.1016/S0304-3940(01)02366-7

Jin LE, Wang M, Yang ST, Yang Y, Galvin VC, Lightbourne TC, Ottenheimer D, Zhong Q, Stein J, Raja A, et al. 2017. MGluR2/3 mechanisms in primate dorsolateral prefrontal cortex: evidence for both presynaptic and postsynaptic actions. Mol Psychiatry 22: 1615-1625. doi:10.1038/mp.2016.129

Jung MW, Qin Y, McNaughton BL, Barnes CA. 1998. Firing characteristics of deep layer neurons in prefrontal cortex in rats performing spatial working memory tasks. Cereb Cortex 8: 437-450. doi:10.1093/cercor/8.5 .437

Kealy J, Commins S. 2011. The rat perirhinal cortex: a review of anatomy, physiology, plasticity, and function. Prog Neurobiol 93: 522-548. doi:10 .1016/j.pneurobio.2011.03.002

Kim SH, Kim MK, Yu HS, Kim HS, Park IS, Park HG, Kang UG, Kim YS. 2010. Electroconvulsive seizure increases phosphorylation of PKC substrates, including GAP-43, MARCKS, and neurogranin, in rat brain. Prog Neuro Psychopharmacol Biol Psychiatry 34: 115-121. doi:10.1016/j.pnpbp.2009 .10 .009

Lee I, Park S-B. 2013. Perirhinal cortical inactivation impairs object-in-place memory and disrupts task-dependent firing in hippocampal CA1, but not in CA3. Front Neural Circuits 7: 134. doi:10.3389/fncir.2013.00134

Li Z, Chen X, Wang T, Gao Y, Li F, Chen L, Xue J, He Y, Li Y, Guo W, et al. 2018. The corticostriatal adenosine A $2 \mathrm{~A}$ receptor controls maintenance and retrieval of spatial working memory. Biol Psychiatry 83: 530-541. doi:10.1016/j.biopsych.2017.07.017

Lind J, Enquist M, Ghirlanda S. 2015. Animal memory: a review of delayed matching-to-sample data. Behav Processes 117: 52-58. doi:10.1016/j .beproc.2014.11.019

Manoach DS, Schlaug G, Siewert B, Darby DG, Bly BM, Benfield A, Edelman RR, Warach S. 1997. Prefrontal cortex fMRI signal changes are correlated with working memory load. Neuroreport 8: 545-549. doi:10 $.1097 / 00001756-199701200-00033$

Morgan JI, Curran T. 1991. Stimulus-transcription coupling in the nervous system: involvement of the inducible proto-oncogenes fos and jun.
Anпи Rev Neurosci 14: 421-451. doi:10.1146/annurev.ne.14.030191 .002225

Park JC, Bae JW, Kim J, Jung MW. 2019. Dynamically changing neuronal activity supporting working memory for predictable and unpredictable durations. Sci Rep 9: 15512. doi:10.1038/s41598-019-52017-8

Paxinos G, Watson C. 2005. The rat brain in stereotaxic coordinates, 6 th ed. Academic Press, New York.

Radley JJ, Anderson RM, Cosme CV, Glanz RM, Miller MC, Romig-Martin SA, LaLumiere RT. 2015. The contingency of cocaine administration accounts for structural and functional medial prefrontal deficits and increased adrenocortical activation. J Neurosci 35: 1189711910. doi:10.1523/JNEUROSCI.4961-14.2015

Runyan JD, Moore AN, Dash PK. 2005. A role for prefrontal calcium-sensitive protein phosphatase and kinase activities in working memory. Learn Mem 12: 103-110. doi:10.1101/1m.89405

Schneider CA, Rasband WS, Eliceiri KW. 2012. NIH Image to ImageJ: 25 years of image analysis. Nat Methods 9: 671-675. doi:10.1038/nmeth .2089

Seamans JK, Lapish CC, Durstewitz D. 2008. Comparing the prefrontal cortex of rats and primates: insights from electrophysiology. Neurotox Res 14: $249-262$. doi:10.1007/BF03033814

Sloan HL, Good M, Dunnett SB. 2006. Double dissociation between hippocampal and prefrontal lesions on an operant delayed matching task and a water maze reference memory task. Behav Brain Res 171: 116 126. doi:10.1016/j.bbr.2006.03.030

Stout SC, Boughner RL, Papini MR. 2003. Reexamining the frustration effect in rats: aftereffects of surprising reinforcement and nonreinforcement. Learn Motiv 34: 437-456. doi:10.1016/S0023-9690(03)00038-9

Sun MK, Alkon DL. 2014. The 'memory kinases': roles of PKC isoforms in signal processing and memory formation. Prog Mol Biol Transl Sci 122: 31-59. doi:10.1016/B978-0-12-420170-5.00002-7

Toepper M, Gebhardt H, Bauer E, Haberkamp A, Beblo T, Gallhofer B, Driessen M, Sammer G. 2014. The impact of age on load-related dorsolateral prefrontal cortex activation. Front Aging Neurosci 6: 9. doi:10 $.3389 /$ fnagi.2014.00009

van Vugt B, van Kerkoerle T, Vartak D, Roelfsema PR. 2020. The contribution of AMPA and NMDA receptors to persistent firing in the dorsolateral prefrontal cortex in working memory. J Neurosci 40: 2458 2470. doi:10.1523/JNEUROSCI.2121-19.2020

Vertes RP. 2004. Differential projections of the infralimbic and prelimbic cortex in the rat. Synapse 51: 32-58. doi:10.1002/syn.10279

Viena TD, Linley SB, Vertes RP. 2018. Inactivation of nucleus reuniens impairs spatial working memory and behavioral flexibility in the rat. Hippocampus 28: 297-311. doi:10.1002/hipo.22831

Vijayraghavan S, Wang M, Birnbaum SG, Williams GV, Arnsten AFT. 2007. Inverted-U dopamine D1 receptor actions on prefrontal neurons engaged in working memory. Nat Neurosci 10: 376-384. doi:10.1038/ nn1846

Vorhees CV, Williams MT. 2014. Assessing spatial learning and memory in rodents. ILAR J 55: 310-332. doi:10.1093/ilar/ilu013

Wang F, Flanagan J, Su N, Wang L-C, Bui S, Nielson A, Wu X, Vo H-T, Ma X-J, Luo Y. 2012. A novel in situ RNA analysis platform for formalin-fixed, paraffin-embedded tissues. JMDI 14: 22-29.

Wang M, Yang Y, Wang CJ, Gamo NJ, Jin LE, Mazer JA, Morrison JH, Wang XJ, Arnsten AFT. 2013. NMDA receptors subserve persistent neuronal firing during working memory in dorsolateral prefrontal cortex. Neuron 77: 736-749. doi:10.1016/j.neuron.2012.12.032

Wiig KA, Bilkey DK. 1994. Perirhinal cortex lesions in rats disrupt performance in a spatial DNMS task. Neuroreport 5: 1405-1408

Wiig KA, Burwell RD. 1998. Memory impairment on a delayed non-matching-to-position task after lesions of the perirhinal cortex in the rat. Behav Neurosci 112: 827-838. doi:10.1037/0735-7044.112.4.827

Wikenheiser AM, Schoenbaum G. 2016. Over the river, through the woods: cognitive maps in the hippocampus and orbitofrontal cortex. Nat Rev Neurosci 17: 513-523. doi:10.1038/nrn.2016.56

Woodcock EA, Anand C, Khatib D, Diwadkar VA, Stanley JA. 2018. Working memory modulates glutamate levels in the dorsolateral prefrontal cortex during 1H fMRS. Front Psychiatry 9: 66. doi:10.3389/fpsyt.2018.00066

Wouterlood FG, Saldana E, Witter MP. 1990. Projection from the nucleus reuniens thalami to the hippocampal region: light and electron microscopic tracing study in the rat with the anterograde tracer Phaseolus vulgaris-leucoagglutinin. J Comp Neurol 296: 179-203. doi:10 $.1002 /$ cne.902960202

Yang ST, Shi Y, Wang Q, Peng JY, Li BM. 2014. Neuronal representation of working memory in the medial prefrontal cortex of rats. Mol Brain 7: 61 . doi:10.1186/s13041-014-0061-2

Received June 19, 2020; accepted in revised form August 17, 2020. 


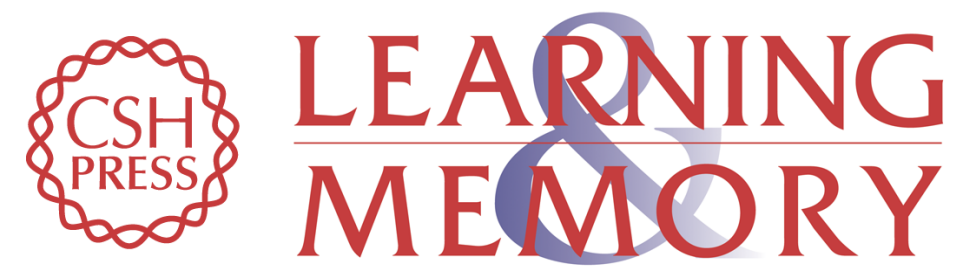

\section{Using rat operant delayed match-to-sample task to identify neural substrates recruited with increased working memory load}

Christina Gobin, Lizhen Wu and Marek Schwendt

Learn. Mem. 2020, 27:

Access the most recent version at doi:10.1101/Im.052134.120

References This article cites 76 articles, 12 of which can be accessed free at: http://learnmem.cshlp.org/content/27/11/467.full.html\#ref-list-1

Creative This article is distributed exclusively by Cold Spring Harbor Laboratory Press for the Commons License first 12 months after the full-issue publication date (see

http://learnmem.cshlp.org/site/misc/terms.xhtml). After 12 months, it is available under a Creative Commons License (Attribution-NonCommercial 4.0 International), as described at http://creativecommons.org/licenses/by-nc/4.0/.

Email Alerting Receive free email alerts when new articles cite this article - sign up in the box at the Service top right corner of the article or click here. 